\title{
Exploring the Impact of IT Service Management Process Improvement Initiatives: A Case Study Approach
}

\author{
Marko Jäntti ${ }^{1,3}$, Terry Rout ${ }^{2}$, Lian Wen ${ }^{1}$, Sanna Heikkinen ${ }^{3}$, and Aileen \\ Cater-Steel $^{4}$ \\ 1 Griffith University, Nathan, School of Information and Communication Technology \\ 170 Kessels Road, Nathan, Brisbane, Queensland 4111, Australia \\ 1.wen@griffith.edu.au \\ 2 Griffith University, Nathan, Institute of Integrated and Intelligent Systems \\ t.rout@griffith.edu.au \\ 3 University of Eastern Finland, School of Computing \\ P.O Box 1627, 70211, Kuopio, Finland \\ \{marko.jantti, sanna.heikkinen\}@uef.fi \\ 4 School of Information Systems \\ University of Southern Queensland \\ Toowoomba, QLD 4350 Australia \\ caterst@usq.edu.au
}

\begin{abstract}
IT companies worldwide have started to improve their service management processes based on best practice frameworks, such as IT Infrastructure Library (ITIL). However, many of these companies face difficulties in demonstrating the positive outcomes of IT service management (ITSM) process improvement. This has led us to investigate the research problem: What positive impacts have resulted from IT service management process improvement? The main contributions of this paper are 1) to identify the ITSM process improvement outcomes in two IT service provider organizations and 2) provide advice as lessons learnt.
\end{abstract}

Keywords: IT service management, service, IT Infrastructure Library, process improvement, process

\section{Introduction}

Thousands of IT organizations worldwide have started to improve their service management processes based on the IT Infrastructure Library (ITIL) that is the most widely used best practice framework for IT service management (ITSM). A major challenge is how people responsible for process improvement can demonstrate the benefits that process improvement initiatives provide. We propose that ITSM standards (15504-8 [1] and ISO/IEC 20000 [2]) provide an opportunity to benchmark current processes and discern improvement.

Evidence on positive impacts of ITSM process improvement motivates employees to participate in the process improvement sessions and training in future, 
enables process improvement specialists to see that their work is meaningful and provide managers with the cost justification regarding the process improvement. IT service management can be broadly defined as "implementation and management of quality IT services that meet the needs of the business" [3]. Examples of IT services are, for example, application and server services.

Currently, there are three different versions of the ITIL framework that organizations use: ITIL V2 2002, V3 2007 and V3 2011 edition. Many IT organizations started the ITSM process improvement by using ITIL v2. The core of ITIL v2 comprised two parts: 1) Service Delivery [4] and 2) Service Support [5].

The ITIL V3 framework was released in 2007 with a completely new structure. The goal of restructuring was to emphasize the service lifecycle with five core lifecycle books. The V3 2011 edition did not provide major amendments but clarified unclear issues in V3 processes. The V3 2011 edition consists of five books: Service Strategy [6], Service Design [7], Service Transition [8], Service Operation [9] and Continual Service Improvement [10].

Because ITIL is a best practice framework, not a standard, IT organizations need an international standard to audit their ITSM processes. The most popular IT service management standard is the ISO 20000 standard family, especially ISO/IEC 20000-1:2010 Part 1: Service management system requirements [2] and ISO/IEC 20000-2:2011 Part 2: Guidance on the application of service management systems [11]. The service management process reference model can be found in the Part 4 [12]. ISO/IEC TS 15504-8:2012 process assessment model [1] expands the PRM process definitions and defines Generic Practices, Generic Resources and Generic Input/Outputs for evaluating the service management process capability. Additionally, it uses Base Practices and Input/Output Information Items as process performance indicators and introduces a Process Maturity Framework (PMF). This standard will be renumbered to fit in the ISO/IEC 33001 family. Figure 1 shows the contribution of ITSM frameworks and standards.

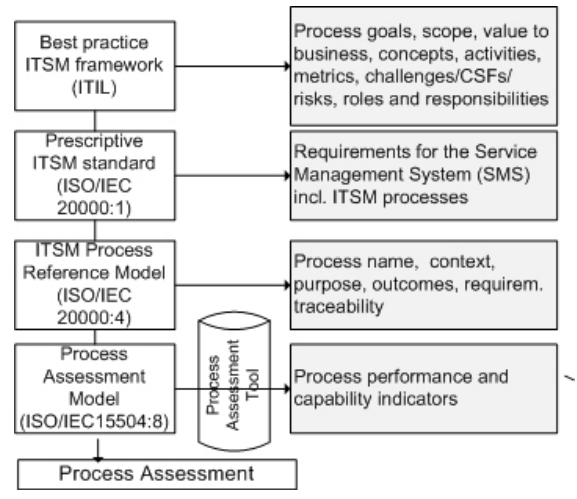

Fig. 1. IT service management process frameworks and standards 
Key Performance Indicators can be used to evaluate whether improvements have resulted in positive outcomes. In the IT service management framework ITIL, the measurement is divided into three elements [3]: Critical Success Factors (CSFs) that represent business objectives for IT service management, Key Performance Indicators that indicate the direction of performance, and metrics that enable measurements in practice.

Previous studies on ITSM implementations have dealt with measurements of ITIL implementation projects [13], the success factors of ITSM projects [14], failures of ITIL implementation [15], maturity models of ITIL implementation [16] and integration of ITIL and CMMi [17]. CMMi for Services [18] can be used to assess the maturity of a service provider organization. Additionally, a recent study in Australia presented a model to select processes for ITSM improvement [19].

Surprisingly few studies have investigated realization of the benefits. Marrone and Kolbe [20] have identified six most important benefits from ITSM implementation: improvement in customer satisfaction, improvement in internal processes, standardization of processes, improvement in service quality, increase in efficiency, and improvement in return on investment (ROI). Lepmets et al. [21] have described the IT service quality attributes that could be measured to improve IT service quality. Barafort et al. [22] have explored the benefits from the use of ISO/IEC 15504 and ITIL. Additionally, McNaughton et al. [23] use a holistic evaluation framework for ITSM with four perspectives: management, technology, IT user, IT employee. There are also studies that have dealt with benefits from improving software development processes. The DACS report [24] presents the following measures for software process improvements: productivity, quality, rework, project cost, improvement cost, cycle time, schedule variance. Similarly, SEI [25] has used cost, schedule, productivity, quality, customer satisfaction, and ROI to measure CMMI-based process improvement.

The main contribution of this paper is to

- explore the impacts of IT service management process initiatives in two IT service provider organizations,

- provide lessons learnt from two cases and

- discuss how to demonstrate ITSM process improvement impacts.

Our research results might be useful for CSI managers, quality managers and process managers responsible for improving service management processes.

The rest of the paper is organized as follows. In Section 2, the research methods are described. In Section 3, we explore the IT service management process improvement impacts. In Section 4 lessons learnt are derived from the analysis of two cases. The conclusions are given in Section 5 .

\section{Research Methods}

In this paper, the research problem is: What positive impacts have resulted from IT service management process improvement? We used a case study research 
method to explore the research problem. This exploratory study was carried out with two organizations. In order to maintain the anonymity of research, they are called Alpha and Beta in this paper. Both organizations were representative cases with ITIL-based process improvement experience. For the IT service management research, a case study method suits especially well because it allows rich data collection on service management processes, people, services, tools and technologies. Eisenhardt has defined a case study as "a research strategy which focuses on understanding the dynamics present with single settings" [26]. The research problem was addressed by the following research questions that provided a roadmap for the case study:

1. What was the scope of process improvement (ITSM processes/ services)?

2. Which quality frameworks/standards or metrics were used to support ITSM process improvement?

3. What effects / benefits / improvements were identified from ITSM process improvement?

4. What effects resulted from IT service management training?

5. What challenges arise in ITSM process improvement?

The training-related question was added to the study because researchers considered ITSM training as an important source of improvement ideas.

\subsection{The Case Organizations and Data Collection Methods}

Our first case organization Alpha offers IT, product development and consulting services in Northern Europe. The company has around 18,000 employees operating in 30 countries. This case study was carried out in the business unit that provides solutions and services for Scandinavian energy companies. The following data sources were used:

- Interview on ITSM impacts: Release and testing manager

- Documentation: SLA, SLM process description, SLA module user guide

- Archives and records: Excel sheets on incident resolution times

- Participative observation: SLA/SLM process improvement meetings (November 2011-January 2012), SLA workshop

- Physical artifacts: Access to intranet and the SLA module (ITSM tool).

Our second case organization Beta provides IT services (e.g. desktop services, service desk) to a government agency. The agency had 5,300 fulltime employees in 2011. The following sources of evidence were used in data collection:

- Interview on ITSM impacts: Service director

- Documentation: Process descriptions, user support metrics, service desk system user manual, service descriptions, service area catalogue

- Archives and records: Incident service request and problem records

- Participative observation: Discussions in weekly meetings

- ITSM training for user support staff: 70 persons (September 2011)

- Physical artifacts: Intranet and a service desk system. 


\subsection{Data Analysis}

In this study, a case comparison analysis technique [26] was used. Regarding both case organizations, information on process improvement events was stored in the KISMET project's case study datastore. We used three different ways of triangulation (multiple sources of evidence): method triangulation, researcher triangulation and data triangulation. Case study findings were validated with the case organization's representatives in validation meetings (2 hours). Interviews were carried out by one researcher but analyzed by two researchers. Case comparison was based on the predefined categories: scope of improvement, process improvement frameworks, achieved benefits, impact of ITSM training, and challenges.

\section{Exploring the Impact of IT Service Management Process Initiatives}

In this section, we explore the IT service management improvements in two Finnish IT organizations. The research findings are presented in the same order as the research questions.

\subsection{What was the scope of process improvement (ITSM processes/ services)?}

Improvements at Alpha targeted all IT service management processes but the research team focus was on two processes: release management and service level management (SLM). Release management aims to ensure that hardware and software releases are planned, implemented, tested delivered in a systematic manner. Regarding the SLM, the research goal was to study how the IT service management tool supports the service level management process. In Beta, ITSM process improvement had focused on service operation processes, such as incident management, knowledge \& problem management, and service request management. Additionally, the goal was to improve the service desk tool to better meet ITSM requirements and organization's needs.

\subsection{Which quality frameworks / metrics were used in ITSM process improvement?}

The interview with Alpha's release and testing manager revealed that, besides ITIL V2 and V3, CMMI, Lean Management principles and ISO 9000 were used in process improvement work. Alpha used an operational framework where the ITIL processes and activities were customized to meet the organization's business needs. The interviewee in Alpha also mentioned the role of own experience and knowhow in the process improvement. In Beta, ITIL was used for guidance during the improvement. Additionally, Beta had used a wide range of 
its own improvement practices to support IT service management process improvement. The following metrics were used to support IT service management process improvement in Alpha and Beta: error trends (Alpha), reaction times (Alpha), resolution times (Alpha, Beta), number of service desk cases (Beta), other productivity metrics (Beta), customer satisfaction (Alpha, Beta) and staff satisfaction (Alpha, Beta).

\subsection{What effects / benefits were identified from ITSM process improvement?}

The interviewees listed the following effects, benefits, and improvements from IT service management processs improvement.

- "Our processes have become more unified" (Alpha)

- "More unified work practices" (Alpha)

- "Number of defects has decreased" (Alpha)

- "The roles of people have become clearer" (Alpha)

- "Shorter resolution times" (Alpha)

- "Customer satisfaction has increased" (Alpha)

- "Staff satisfaction has increased" (Alpha)

- "Staff satisfaction has improved" (Beta)

- "IT service management knowhow has increased" (Beta)

- "Better understanding of critical elements of the service" (Beta)

- "Improved collaboration" (Beta)

- "Decreased number of defects" (Beta)

- "Positive feedback from customers" (Beta)

- "Better transparency of operations" (Beta)

- "Better atmosphere among staff" (Beta)

- "Increased customer satisfaction" (Beta)

- "A better monitoring system for service management" (Beta)

- "Better IT service quality" (Beta)

- "Reduced number of contacts from customers" (Beta).

\subsection{What effects resulted from IT service management training?}

Alpha's interviewee stated that as a result of IT service management training, the awareness of ITIL practices had increased. Additionally, training helped people to use common terminology and concepts. Three types of training had been organized in Alpha: ITSM training organized by the university's ITSM research team, in-house training and the official ITIL training (ITIL Foundation) provided by consultancy companies. The SLA training was organized in January, 2012 for customer service representatives. The training started with a case organization's presentation on why SLAs are important for business. The second presentation was held by a researcher who demonstrated the features of the SLA module. The participants had already received earlier some ITIL process training. The following list shows examples of questions that were asked during the training. 
- "How are reopened cases handled in SLA measurement?"

- "Is creating a workaround included in the SLA time?"

- "Which request states are included in the SLA?"

- "Who is responsible for changing the case urgency?"

- "Who should receive information on SLA alerts?"

- "What calendar date should we use for SLAs?"

The outcome of this training was that case organization's employees were now able to create SLAs and configure SLA rules for new customers.

Beta's interviewee commented that ITSM training has been considered useful in the organization but also stated that integration of training to the organization's processes is very important because many IT support staff have difficulty following theory-oriented IT service management training. IT service management awareness training in Beta was conducted for 70 people in different locations. Additionally, some employees and management had participated in official ITIL certification training. We observed that inhouse ITSM training provided much more discussion compared to online training. Next, we present some interesting questions that were captured during the training sessions:

- "How do we react in cases that would require immediate solution but specialist teams tell us that the solution shall come after a week or two?"

- "How should we solve cases where a user contacts the service desk and reports that he/she still has the same incident. Should we reopen the case?"

- "Has a rule for reopening cases been documented somewhere?"

- "The testing unit delivers the known errors from testing as Excel reports. It would be nice if known errors could be stored in the service desk system"

- "We should think about the need for the official ITIL certification training"

- "Earlier it has seemed that process frameworks are only for managers. Now, it looks like they are coming to the field work, too"

- "We should think about the metrics from our group's perspective".

The outcome of this training was that case organization's employees became aware of ITSM practice, identified some bottlenecks in their current practices and some workers also became motivated to pursue more ITSM training.

\subsection{What challenges arise in ITSM process improvement?}

The case organizations listed the following challenges regarding IT service management process improvement:

- To get enough knowledge on the operational environment, challenges and risks in order to scope the services successfully (Alpha)

- Managing changes in manageable portions (Alpha)

- Clarification of roles and responsibilities to avoid extra work (Alpha)

- Unified working practices (Alpha)

- Management of change and consistent management (Alpha)

- One has to find an appropriate management model for change and service delivery, not too complex or too detailed (Beta) 
- How to apply the ITSM models and frameworks to our own business (Beta)

- Introduction of ITSM processes is challenging (Beta)

- The size of the product development teams is 3-70, thus, it is difficult to describe unified processes that suit everybody (Beta)

- People do not want to give up old work practices (Beta)

- Often, it is challenging to implement changes in such a way that span process boundaries (Beta)

- People do not always see the benefits from process improvement. It may be considered as extra work without understanding benefits (Beta)

- In order to get people to adopt the processes, they have to participate in the process improvement work (Beta).

\section{Analysis}

In the analysis phase, we compared the findings from Alpha and Beta based on five categories (scope of process improvement, quality frameworks or standards used in ITSM process improvement, achieved benefits from improving ITSM processes, impact of ITSM training, and process improvement challenges) and converted the findings to lessons learnt. A source for each lesson is presented in parentheses $(\mathrm{AR}=$ Archives and records, $\mathrm{D}=$ Documentation, $\mathrm{ID}=$ Interviews and discussions, $\mathrm{O}=$ Observation, $\mathrm{PA}=$ physical artefacts, $\mathrm{ST}=$ Seminars and training organized by the research group).

Lesson 1: People have difficulty understanding the benefits from process improvement (RQ1: ID, O, ST). The improvement scope in Alpha was release management and service level management and in Beta incident management and service support. Interviews, observations and some ITSM training sessions revealed that some employees have difficulties understanding the benefits from process improvement. Management has to continuously market the benefits of ITSM process improvement. Basically, there are three simple ways how to identify potential ITSM benefits. First, an organization could carry out an ITSM process assessment based on ISO/IEC 15504-8 to provide a benchmark. The second way is to check the defined benefits from best practice frameworks, such as ITIL and COBIT, and to analyze whether the organization has achieved these benefits. The third way is to ask the customers whether they see improvements in service delivery.

Lesson 2: ITSM process improvements do not always show direct monetary benefits (ID). We expected that organizations would have shown stronger interest in the financial aspects of process improvement. Interviewees in Alpha and Beta mentioned the increase in productivity instead of cost savings and return on investment. For example, ITIL addresses four basic concepts to measure service management improvements [3], [10]: Improvements, Benefits, ROI (Return on Investment), and VOI (Value on Investment). Improvements can be analyzed by comparing the 'before' state to the 'after' state based on selected metrics (for example, 10 per cent increase in customer satisfaction on incident resolutions). Benefits mean realization of improvements. They can be 
analyzed from a financial perspective (costs or profits). ROI can be measured by calculating the difference between the benefit (saving) achieved and the amount expended. VOI means the extra value that improvement provides for business, such as improved communication or collaboration with customers (a metric in this case could be a number of meetings with a customer).

Lesson 3: IT organizations measure improvements through customer and staff satisfaction, and operational metrics (O, D, ID). Common process improvement metrics in Alpha and Beta were customer satisfaction and staff satisfaction, and operational metrics such as resolution times. We propose that organizations could easily establish a measurable process improvement framework by combining three concepts: Critical Success Factors, Key Performance Indicators and Metrics. For example, an organization might select the following CSF, KPI and metric: Quickly resolve incidents (CSF); Reduction in average time to respond to a call (KPI); Average call response time per month (Metric). The KPI from our example can be now used to define a measurable process improvement goal, such as $10 \%$ reduction in call response time.

Lesson 4: Management and integration of multiple process improvement frameworks is a challenge (RQ2: ID, O). There is a large number of process improvement frameworks, models and standards available for organizations seeking to improve ITSM processes. According to our interviews, management considered it challenging to select an appropriate framework or a standard to carry out changes to processes, such as Alpha's comment showed: "One has to find an appropriate management model for change and service delivery, not too complex or too detailed". It seems that future ITSM frameworks need to have interfaces to multiple frameworks and models, such as Agile, Lean and Cloud Service models.

Lesson 5: ITSM improvement results in positive outcomes (RQ3: ID). The following benefits were identified based on the interviews with Alpha and Beta: customer satisfaction, staff satisfaction, service management culture, higher process maturity / more standard process, improved tools and technologies, standardized services, increased service quality, increased efficiency / productivity, cost savings, better transparency.

Lesson 6: ITSM training provides valuable inputs to CSI (RQ4: ST). Management should pay attention to ITSM training and avoid organizing training in large groups to save time and costs. We observed that when trainees were motivated and training was organized in-house in small groups, they identified important bottlenecks in their daily service management practices. These bottlenecks should be considered for Continual Service Improvement.

Lesson 7: Use novel approaches to decrease the complexity of ITSM standards (RQ5: ID, ST). Interviews, discussions and training events revealed that ITSM standards and frameworks are often considered too complex and bureaucratic because of special jargon. However, they provide an excellent way to demonstrate that the process is more mature than before improvement actions. We propose that using visual notation, such as Behavior Engineering, to model requirements can remarkably decrease the feeling of complexity and lead 
to faster understanding of requirements. Behavior Engineering can be defined as "an integrated discipline that supports the systems and software engineering of large-scale, dependable software-intensive systems" [27]. Figure 2 shows a CT diagram we created for ISO/IEC 20000 Problem Management Requirement 1 [2]: There shall be a documented procedure to identify problems and minimize or avoid the impact of incidents and problems.

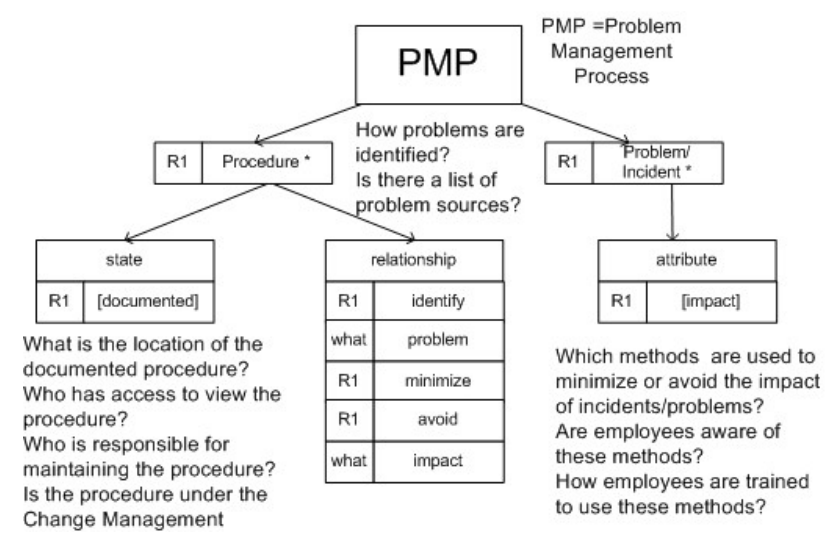

Fig. 2. A composition tree for ISO/IEC 20000 Problem Management, Requirement 1

Lesson 8: Lack of tools for demonstrating benefits (RQ5: O, PA). Based on our observations, it seems that organizations lack effective tools to demonstrate ITSM process improvement benefits or assess the maturity of processes. There are very few tools available. A valuable tool for process assessment is provided by AssessmentPortal [28]. One of the tool features is a Service Provision perception survey that explores the different views of service provision from both and IT and Business perspective. The Appraisal Assistant tool by Software Quality Institute can be used to support process assessment (ISO/IEC 15504, CMMI) [29].

These lessons learnt were not presented in a priority order. Our previous knowledge on cases may have been reflected in the findings. In future, we aim to extend this exploratory study to other IT service provider organizations to gain a richer view on the ITSM process improvement outcomes.

\section{Conclusions}

The research problem in this study was: What positive impacts have resulted from IT service management process improvement? The main contribution of this study is real-world examples of effects and benefits of ITSM improvement initiatives and training, and the challenges faced by organizations seeking improvements. The following impacts were identified: customer satisfaction, staff 
satisfaction, service management culture, higher process maturity / more standard process, improved tools and technologies, standardized services, increased service quality, increased efficiency / productivity, cost savings, and better transparency of operations.

This study included the following limitations. First, we included two organizations in our study. A higher number of cases would have provided the potential to generalize the results. Second, data was collected mainly by qualitative methods such as interviews, observation and analyzing the companies' documentation. Most of the lessons were based on interviews and discussions. Quantitative data, for example, on metrics and measurements, would have provided a richer view on the organizations. Finally, interviews were conducted only with managers. Staff interviews might have provided additional perspectives.

To conclude, more case studies are needed to examine positive impacts of IT service management process improvement. Further work could focus on creating and validating a systematic impact assessment model for ITSM process improvement initiatives.

\section{Acknowledgment}

This paper is based on research in Keys to IT Service Management and Effective Transition of Services (KISMET) project funded by the National Technology Agency TEKES (no. 70035/10), European Regional Development Fund (ERDF), and industrial partners.

\section{References}

1. ISO/IEC TS 15504-8:2012: Information technology - Process assessment -Part 8: An exemplar process assessment model for IT service management. ISO/IEC TC JTC1/SC7 Secretariat (2012)

2. ISO/IEC 20000:1: Part 1: Service management system requirements. ISO/IEC JTC 1 Secretariat (2010)

3. Office of Government Commerce(e): ITIL Continual Service Improvement. The Stationary Office, UK (2007)

4. Office of Government Commerce: ITIL Service Delivery. The Stationary Office, UK (2002)

5. OGC: ITIL Service Support. The Stationary Office, UK (2002)

6. Cabinet Office: ITIL Service Strategy. The Stationary Office, UK (2011)

7. Cabinet Office: ITIL Service Design. The Stationary Office, UK (2011)

8. Cabinet Office: ITIL Service Transition. The Stationary Office, UK (2011)

9. Cabinet Office: ITIL Service Operation. The Stationary Office, UK (2011)

10. Cabinet Office: ITIL Continual Service Improvement. The Stationary Office, UK (2011)

11. ISO/IEC 20000:2: Part 2: Guidance on the application of service management systems. ISO/IEC JTC 1 Secretariat (2011)

12. ISO/IEC TR 20000-4:2010: Information technology - Service management - Part 4: Process Reference Model. Geneva, Switzerland, International Organization for Standardization (2010) 
13. Iden, J., Eikebrokk, T.R.: Understanding the ITIL implementation project: Conceptualization and measurements. In: Proceedings of 2011 22nd International Workshop on Database and Expert Systems Applications, Washington, DC, USA, IEEE (2011)

14. Tan, W.G., Cater-Steel, A., Toleman, M.: Implementing IT service management: A case study focussing on critical success factors. Journal of Computer Information Systems 50(2) (2009)

15. Sharifi, M., Ayat, M., Rahman, A.A., Sahibudin, S.: Lessons learned in ITIL implementation failure. In: Information Technology, 2008. ITSim 2008. International Symposium. Volume 1. (2008) 1-4

16. de Sousa Pereira, R., da Silva, M.: A maturity model for implementing ITIL v3. In: Services (SERVICES-1), 2010 6th World Congress on. (2010) 399 -406

17. Latif, A.A., Din, M.M., Ismail, R.: Challenges in adopting and integrating ITIL and CMMi in ICT division of a public utility company. Computer Engineering and Applications 1 (2010) 81-86

18. Software Engineering Institute: Capability Maturity Model Integration for Services v1.3. Carnegie Mellon University (2010)

19. Shrestha, A., Cater-Steel, A., Tan, W.G., Toleman, M.: A model to select processes for IT service management improvement. In: Proceedings of the 23rd Australasian Conference on Information Systems, Deakin University (2012)

20. Marrone, M., Kolbe, L.: Impact of IT service management frameworks on the IT organization: An empirical study on benefits, challenges, and processes. Business \& Information Systems Engineering Journal 3(Iss. 1) (2011) 5-18

21. Lepmets, M., Cater-Steel, A., Gacenga, F., Ras, E.: Extending the IT service quality measurement framework through a systematic literature review. Journal of Service Science Research 4 (2012) 7-47

22. Barafort, B., DiRenzo, B., Merlan, O.: Benefits resulting from the combined use of ISO/IEC 15504 with the Information Technology Infrastructure Library (ITIL). In: Proceedings of the Product Focused Software Process Improvement Conference 2002. 2559, Springer-Verlag (2002) 314-325

23. McNaughton, B., Ray, P., Lewis, L.: Designing an evaluation framework for IT service management. Information Management 47 (2010) 219-225

24. McGibbon, T., Ferens, D., Vienneau, R.: A business case for software process improvement (2007 update): Measuring return on investment from software engineering and management. Technical report, DACS Report (2007)

25. Gibson, D., Goldenson, D., Kost, K.: Performance results of CMMIß-based process improvement. CMU/SEI-2006-TR-004, Carnegie Mellon University / Software Engineering Institute (2006)

26. Eisenhardt, K.: Building theories from case study research. Academy of Management Review 14 (1989) 532-550

27. Behavior Engineering website: Behavior engineering. http://www.behaviorengineering.org/ (2012)

28. Assessment Portal: Assessment portal website. http://assessment-portal.com/ (2012)

29. Rout, T.: Studies on the assessment process: Usage of objective evidence in assessing process capability. In: Proceedings of the Software Process Improvement and Capability Determination - 9th International Conference: SPICE 2009, Turku Centre for Computer Science, Turku, Finland (2009) 